\title{
Measurement of color preference in goldfish using a negative reinforcement Y-maze avoidance procedure
}

\author{
DOMINIC J. ZERBOLIO, JR. \\ University of Missouri, St. Louis, Missouri 63121
}

\begin{abstract}
Using a Y-maze procedure involving shock reinforcement, goldfish were forced to choose between a red or a green cued arm of the maze. Although the 18 animals tested showed, as a group, an average green preference, equal numbers of animals showed individual green (6), red (6), and no-color (6) preferences. Differences between conclusions based on group means against individual performances are noted. In goldfish, at least, the shock-reinforced Y-maze procedure may represent a very useful technique for further color preference assessment.
\end{abstract}

In a Y-maze, in which different colored light cues were presented simultaneously, goldfish learned to swim to the color cue associated with shock omission $\left(\mathrm{S}^{+}\right)$ rather than shock presentation $\left(\mathrm{S}^{-}\right)$(Zerbolio \& Wickstra, 1979). Half of the animals run had a green $\mathrm{S}^{+}$and red $\mathrm{S}^{-}$; the remainder had the reverse, a red $\mathrm{S}^{+}$and green $\mathrm{S}^{-}$. The analysis found avoidance acquisition to be equivalent, in that goldfish learned to swim to the $\mathrm{S}^{+}$alley just as efficiently with the green $\mathrm{S}^{+} /$red $\mathrm{S}^{-}$ cues as with the red $\mathrm{S}^{+}$/green $\mathrm{S}^{-}$cues. With positive reinforcement, Muntz and Cronly-Dillon (1966) showed a distinct color bias. However, the avoidance data clearly show that goldfish can distinguish between the red and green cues and will learn to swim to the cue associated with shock omission, independent of the color of the cue. But the same piece of equipment may be able to answer another question: Namely, do goldfish have specific color preferences independent of reinforcement? Cue preferences are not uncommon in the literature. Black or dark preferences with rats are a fairly common occurrence. However, to anwer the question for goldfish in the Y-maze, the differential shock-omission reinforcement for a specific color would have to be eliminated since, obviously, it would mask any innate preference.

The Y-maze seems to lend itself well to the assessmentof-preference task because two different cues can be presented simultaneously. If one simply equates the behavioral consequences of selecting one cue over the other and yet still requires the animal to choose, the resulting choice behavior may represent a measure of innate cue preference.

Procedurally, this can be accomplished in the Y-maze by allowing any response involving swimming from the start alley to one of the alternative arms to produce shock omission. In this procedure, the premium is on swimming to one of the alternative cued alleys, but not on which one is selected. The following work was accomplished to see if the technique outlined is sensitive enough to detect color preferences in goldfish, if they exist.

\section{METHOD}

\section{Subjects}

Eighteen 5- to 6-cm goldfish, obtained from Ozark Fisheries, housed in individual $7.5 \times 11.5 \times 12.5 \mathrm{~cm}$ deep aquaria, served as subjects. Housing was well aerated and filtered, with both temperature $\left(21.1^{\circ} \mathrm{C}\right)$ and $\mathrm{pH}(7 \pm .1)$ held constant throughout the experiment. Animals were fed once a day.

\section{Apparatus}

Two identical Y-mazes, completely described in Zerbolio and Wickstra (1979), were used. Illumination was provided in each alley by three $7-\mathrm{W} 110-\mathrm{V}$ ac Christmas tree bulbs, one white, one red, and one green, which could be independently controlled. The US was a $200-\mathrm{msec} 6-\mathrm{V}$ ac $(.695-\mathrm{V} / \mathrm{cm})$ shock delivered through stainless steel plates lining the inside alley walls. Water was maintained at $2 \mathrm{~cm}$ over the hurdle at all times.

\section{Procedure}

Goldfish were tested 60 trials/day for 10 days. The intertrial interval (ITI) varied from 20 to $100 \mathrm{sec}$ with a mean of $60 \mathrm{sec}$. During the ITI, all alleys were illuminated with white light. At trial onset, all white illumination was extinguished. The start alley, or alley occupied by the fish, stayed dark, while simultaneously, the remaining two alleys were illuminated, one red and the other green. The red-illuminated alley occurred equally often on the left or right of the start alley, according to a Gellerman series. Each trial was $11.2 \mathrm{sec}$ long. The animal had $10 \mathrm{sec}$ to leave the start alley and swim to one of the illuminated alternative alleys. If the animal failed to leave the start alley before the $10 \mathrm{sec}$ had elapsed, the US was delivered. The US was two 200 -msec shocks, with an $800-\mathrm{msec}$ period between them. If the animal, responding to the first US pulse, left the start alley in the $800-\mathrm{msec}$ intershock interval, the second US pulse was omitted. If the animal swam from the start alley to either one of the alternative alleys during the 10 -sec period between trial onset and the first US pulse, both US pulses were omitted, and the response was recorded as an avoidance. Shock omission was the only behavioral consequence of the animal's response. On each avoidance response, the color of the initially selected alley was recorded. At the end of $11.2 \mathrm{sec}$, all trial illumination was extinguished, and the ITI (all white) illumination returned to all alleys. All events and responses were programmed and recorded with automated equipment incorporating appropriate circuitry.

\section{RESULTS AND DISCUSSION}

Mean daily total avoidances and daily mean avoidances 


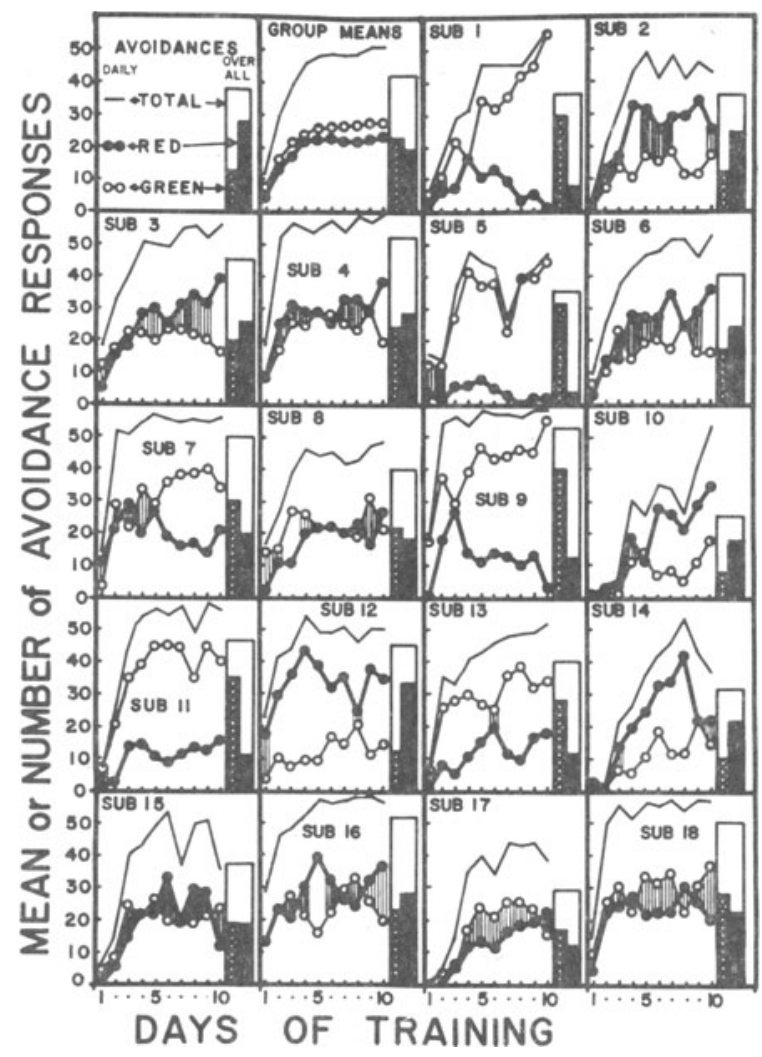

Figure 1. Avoidance performances are shown for the entire group and each individual animal in the group. Group means for total avoidances and avoidances to the red and to the green cued alleys for each day and over all 10 days are shown in the group means panel. Daily total avoidances and avoidances to red and green cued alleys, as well as mean overall avoidances, are shown for each of 18 subjects. For the individual daily performances, equivalent red-green performances are connected by vertical strokes. If red-green performances differed statistically $(p<.05)$, they are not connected.

to the green and red arms of the Y-maze are shown in the group means panel of Figure 1. Figure 1 also shows the total daily and red vs. green avoidances for each individual animal (Subjects 1-18). In addition, each panel of Figure 1 shows the mean performances over all days as a bar graph, which indicates the average total, average green, and average red performance, both for the group as a whole (group means panel) and for each individual subject (1-18).

\section{Group Performance}

As the group means panel shows, goldfish very quickly learn to leave the start alley and approach one of the differently illuminated alternative arms. Also, as a group, a consistent preference for the green cued arm was observed, which did not change with training. These results were confirmed by analysis, which found a significant increase in total avoidance with training $[F(9,153)=195.72, p<.01]$ and a significant green over red preference $[\mathrm{F}(1,17)=12.94, \mathrm{p}<.01]$. How- ever, an analysis of green minus red difference scores confirmed that the green preference did not change with training $(\mathrm{F}<.05)$.

Based on the group analysis, it would seem that, given a choice between red and green alternatives, goldfish, on average, have a significant preference for a green cue. But the "average" preference belies, at least in some cases, the actual idiosyncratic preferences of individual animals. The problems of averaging are expressed in a venerable literature far too extensive to attempt to review here. To appreciate the actual individual red/ green preferences, a second analysis considering individual goldfish performances was completed.

\section{Individual Performances}

Usually, assessment of individual performances is difficult because one does not have a baseline performance to work with. In the present case, for each day for each goldfish, the number of red and number of green alley choices are available. Thus, given the total number of avoidances on each day for each goldfish, direct comparisons of proportion red vs. proportion green against an equal proportion hypothesis was completed for each animal for each day. The results of these comparisons are shown in Figure 1. If, on any given day, the proportion red vs. green responses did not differ, they are connected with vertical strokes. If, however, proportions of red vs. green responses did differ $(p<.05)$, they are not connected. Perusal of the individual performances in Figure 1 shows that about $67 \%$ of the animals have distinctive color preferences. Specifically, Subjects $1,5,7,9,11$, and 13 show decided green preference, Subjects 2, 3, 6, 10, 12, and 14 show decided red preference, and Subjects $4,8,15,16,17$, and 18 show little or no preference.

A comparison of total performances, with total red vs. total green given total avoidances represented by the bar graphs in each panel, was also done. However, since the totals represent a sum across the 10 days of training, criterion levels for $\alpha$ effective $=1-(1-\alpha)^{10}$ (Hays, 1963) were calculated and yielded $Z=2.81,3.08$, and 3.80 as critical values for the $.05, .02$, and .01 levels, respectively. Against these critical values, Subjects 1, $5,7,9,11$, and 13 all showed significant overall green preference $(\mathrm{Z}=11.54,14.71,4.71,12.08,11.47$, and 8.21 , respectively); Subjects $2,3,6,10,12$, and 14 all showed significant overall red preference $(Z=6.16$, $2.83,3.33,6.18,9.79$, and 5.87 , respectively); and the remainder of the subjects $(4,8,15,16,17$, and 18) did not differ overall (all $\mathrm{Zs}<2.81$ ).

From these data it is clear that the modified Y-maze procedure, which requires the goldfish to leave the start alley but does not differentially reinforce what choice is made, is sensitive enough to detect individual color preferences when they occur. Because a negative reinforcer was used, the technique also eliminated any possible reduction in responding that can occur in positive 
reinforcement procedures due to satiation effects. Also, since all recorded and shown responses were avoidances and thus were not shock elicited as a US escape response might be, it seems reasonable to conclude that the observed color choices were actually individual color preferences. This was further supported by the fact that individual animals followed the preferred cue as it randomly occurred, on the left or right of the start alley. One could argue that an initial or early primacy effect accounts for individual preferences, but the data from Subjects 3, 6, 15,16,17, and 18 argue against this, since the initially higher frequency cue (Day 1 of training; see Figure 1) did not become the preferred color, and, despite a decided higher initial frequency of one color, no reliable preference developed.

In any case, these data strongly support the notion that individual goldfish have specific color preferences. Of course, the specific choice here was limited to red and green, but the technique appears promising enough to use with other color comparisons. The technique itself is comparable to a forced-choice procedure. The present data also clearly show that conclusions based on group means do not necessarily reflect what individual animals do. One only has to note that, although the group mean data suggested a green preference, fully
$67 \%$ of the animals tested either had a red preference (six animals) or no preference (six animals). The fact that such clear individual preferences were established also points out the utility of color cues in testing with this animal, a real advantage over color-blind laboratory preparations.

In summary, then, the Y-maze seems to be ideally suited for detecting color preference in goldfish. Certainly, behavioral preferences for gross color differences such as red vs. green are measurable. How sensitive the technique really is and what the limits of color discrimination for this animal are remain as questions for further examination.

\section{REFERENCES}

Hays, W. L. Statistics for psychologists. New York: Holt, Rinehart, \& Winston, 1963.

Muntz, W. R. A., \& Cronly-Dillon, J. R. Colour discrimination in goldfish. Animal Behaviour, 1966, 14, 351-355.

Zerbolio, D. J., JR., \& Wickstra, L. L. Instrumentally based conditioned avoidance response acquisition in goldfish in a simultaneous presentation task. Bulletin of the Psychonomic Society, 1979, 13, 311-313.

(Received for publication December 5, 1979.) 